\title{
ESTILO PARENTAL E VARIÁVEIS PSICOSSOCIAIS COMO FATORES DE RISCO OU PROTECÃO PARA A GRAVIDEZ NA ADOLESCENNCIA
}

RESUMO: O presente estudo de revisão trata da gravidez precoce, que relacionase a problemas psicossociais e econômicos, tais como evasão escolar, conflitos interpessoais e problemas econômicos e emocionais, sendo considerada problema de saúde pública em vários países. O objetivo deste artigo é discutir algumas variáveis psicossociais que atuam como fatores de risco ou proteção para a gravidez na adolescência: os estilos parentais de educação, a educação sexual e história de aprendizagem, bem como a influência exercida pelo grupo de pares e a coexistência de técnicas conflitivas de controle sexual. A partir da análise das pesquisas sobre o tema e do referencial da Análise do Comportamento, entende-se que os estilos parentais negligente, autoritário e permissivo podem favorecer a ocorrência da gravidez na adolescência ao promoverem ambientes coercitivos ou falta de limites, ou ainda dificuldades de autocontrole e baixa autoestima. As agências governamentais, educacionais, religiosas e familiares adotam técnicas e posturas conflitivas, que competem entre si, adotando em alguns casos um padrão mais severo, e em outros posturas liberais, sem o esclarecimento e a coerência necessários para o desenvolvimento da autonomia responsável. Conclui-se que se faz necessária a instrumentalização do adolescente para reagir, de forma assertiva, diante de grupos, parceiros e ambientes coercitivos, a promoção de ambientes familiares respeitosos nas relações afetivas e o desenvolvimento do comportamento responsável por meio de uma educação sexual clara, que evita posturas ambivalentes ou conflituosas no desenvolvimento do autocontrole sexual.

PALAVRAS-CHAVE: Gravidez na adolescência; Práticas educativas; Autocontrole.

\section{PARENTS' ST YLE AND PSYCHO-SOCIAL VARIABLES AS RISK FACTORS OR PROTECTION IN PREGNANCY DURING ADOLESCENCE}

ABSTRACT: Current assay deals with pregnancy at an early age and its relationship to psycho-social and economic issues, such as truancy, interpersonal conflict and

Psicóloga. Mestre em Análise do Comportamento. Docente de Psicologia no Centro Universitário de Maringá (UNICESUMAR), Maringá, Brasil. 
economic and emotional problems. Early pregnancy is considered a public health issue in many countries. Several psychosocial variables, or rather, risk or protection factors in pregnancy during adolescence are discussed. They comprise parents' style in education, sexual education, schooling, influence of friends and coexistence of conflicting techniques of sexual control. Research on the theme and Behavior Analysis show that parents' negligent, authoritarian and permissive styles may favor the occurrence of pregnancy during adolescence when they underscore coercive environments, lack of constraints, difficulties in self-control and low self-esteem. Government, educational authorities, religious associations and families adopt conflicting techniques and postures which compete one against another. In certain cases, they feature a stricter stance, and more liberal ones in other instances, without the necessary coherence for the development of responsible autonomy. Results demonstrate that adolescents should react categorically in the face of groups, partners and coercive environments; they should promote respectable family environments and the development of a responsible behavior through an unambiguous sexual education that avoids ambivalent or conflicting nuances within the development of sexual self-control.

KEY WORDS: Pregnancy during adolescence; Educational practices; Self-control.

\section{INTRODUÇÃO}

A gravidez na adolescência é geralmente considerada indesejada por não ser planejada e muitas vezes repercutir negativamente na vida escolar, familiar, econômica e emocional dos adolescentes. Muitos jovens acabam abandonando os estudos para trabalhar devido às despesas aumentadas ou para cuidar do bebê. Os conflitos familiares podem causar depressão e mesmo ideação suicida (COSTA, 2014; AMORIM, 2009; CRUZ, CARVALHO E IRFFI, 2016; DIAS; GOMES, 2015).

A gravidez precoce tem se mostrado um problema social importante apesar dos investimentos em políticas públicas de educação em saúde e em ações para o planejamento reprodutivo. No Brasil, a porcentagem de partos de adolescentes entre 10 a 19 anos, era de 18\% no ano de 2015, segundo dados do SINASC (Sistema de Informação sobre Nascidos Vivos) do Ministério da Saúde. (DE AZEVEDO et al, 2015; SILVA et al, 2015)

Já há muito tempo pesquisadores tem afirmado a importância da informação sobre sexualidade e métodos contraceptivos para prevenção da gravidez 
na adolescência e, ainda hoje, incentivam o desenvolvimento de ações públicas orientadas neste sentido, conforme vemos nas conclusões do texto recente de Cruz, Carvalho e Irffi, (2016):

Devem ser implementadas políticas públicas que visem tanto aumentar quanto pulverizar o já existente conhecimento sobre sexualidade e reprodução, além de temáticas sobre planejamento familiar, bem como facilitar o acesso aos métodos contraceptivos para que o uso seja efetivo e, com isso, postergar a idade da primeira gestação para a fase adulta em detrimento da adolescência. (p. 261)

Apesar desta tese recorrente que coloca a falta de informação de qualidade como causa principal da gravidez precoce, há mais de uma década outras pesquisas tem mostrado que a maioria dos adolescentes tem informação sobre sexualidade e métodos contraceptivos, e que há outros fatores além da desinformação sobre o assunto, que parecem exercer controle sobre o comportamento sexual do adolescente. (GUIMARÃES; WITER, 2007, AMORIM et al., 2009).

Guimarães e Witer (2007) pesquisaram o conhecimento que 22 adolescentes grávidas tinham sobre contracepção antes da gestação, e encontraram que todas tinham conhecimento sobre prevenção da gravidez, $40 \%$ não havia recebido orientações de um profissional e $60 \%$ sim, mas não o colocaram em prática, indicando pouco êxito das orientações recebidas, ou seja, não tiveram impacto no comportamento das adolescentes. No estudo realizado por Amorin et. al. (2009), que comparou uma amostra de 168 adolescentes grávidas com 337 adultas que formaram o grupo controle, não houve diferença entre casos e controles quanto ao conhecimento de qualquer método anticoncepcional.

A identificação de fatores de risco e proteção para a gravidez na adolescência, e a discussão de propostas e estratégias de intervenção para a prevenção do problema, relacionados às questões sociais e familiares, são objetivos deste estudo de revisão bibliográfica.

\section{CONCEITUAÇÃO E CONSEQUÊNCIAS DA GRAVIDEZ NA ADOLESCÊNCIA}

Sidman; Andery e Sério (1995) apontam para as dificuldades trazidas pela gravidez até mesmo para adultos tais como: intensas mudanças fisiológicas e na 
estética do corpo, preocupações com a saúde da gestante e do bebê, a necessidade de desenvolver um novo repertório de cuidado, adaptação do tempo para este cuidado, despesas adicionais, entre outros.

Quanto à dimensão sociocultural, a gravidez precoce interfere na vida escolar dos futuros pais adolescentes que, frequentemente, abandonam os estudos para assumir as novas obrigações de sustentar e cuidar do bebê (AMORIN, 2009). Silvares (2001) alerta que conflitos interpessoais gerados por consequências do sexo não seguro (doenças venéreas e gravidez) podem levar à tentativa de suicídio por parte de adolescentes incompreendidos.

Haydu (2003) afirma que "a compreensão do desenvolvimento e da adaptação de um indivíduo ao meio em que vive deve envolver a análise de todo o sistema de interações do mesmo, considerando não somente os processos que envolvem os membros de sua comunidade, mas também o ambiente como um todo." Faz-se necessário então empreender análises acuradas do maior número possível de interações estabelecidas pelo adolescente e verificar o controle exercido por outras variáveis, que esteja sobrepujando o efeito do conhecimento do adolescente sobre o assunto.

\section{FATORES DE RISCO E PROTEÇÃO PARA A GRAVIDEZ NA ADOLESCÊNCIA}

Várias pesquisas tem sido realizadas no Brasil e no exterior com o objetivo de determinar fatores de risco associados à gravidez precoce, além de relatos de programas de intervenção para prevenção deste problema (ALMEIDA; ROCHA, 2017; ALVARENGA; WEBER; BOLSONI-SILVA, 2016; AMORIM et al., 2009; GUIMARÃES; WITTER, 2007; SILVA et al., 2013).

Quanto à relação familiar, Santos et al. (2014) encontraram incidência maior (35\%) de mães das adolescentes que também gestaram na adolescência, resultado que concordou com a pesquisa anterior de Amorim et al. (2009).

Dias e Gomes, (2015), analisaram nove famílias, investigando a perspectiva de adolescentes gestantes e de seus pais e encontraram sérias dificuldades comunicativas entre os dois grupos. Estes dados concordam com a pesquisa de Costa 
et al. (2014) cujos resultados indicam pouca comunicação entre pais e adolescentes, vergonha dos pais de falar sobre sexo e medo dos adolescentes de serem punidos por revelar sua experiência ou curiosidade.

Um dos fatores relatados por Guimarães e Witter (2007) como impeditivos do uso do anticoncepcional, foi que o uso de pílulas implicaria no conhecimento dos pais sobre a vida sexual ativa da filha. Nesta mesma pesquisa, os pais ignoravam a existência da vida sexual da filha, e não se consideravam aptos a transmitir conhecimentos úteis aos filhos a respeito de sua sexualidade.

O Instituto de Pesquisa Aplicada (IPEA) desenvolveu pesquisa com base nas informações da Pesquisa Nacional de Demografia e Saúde da Criança e da Mulher (PNDS) de 2006 do Ministério da Saúde (MS) de 2009, que apontou como fatores de proteção para gravidez precoce, o fato de ter sido criada na religião católica ou evangélica, maior escolaridade e residir em regiões mais desenvolvidas, como o sudeste. (CRUZ; CARVALHO; IRFFI, 2016).

Pesquisas tem mostrado a influência dos pais no desenvolvimento de competências dos filhos (GOMIDE, 2001; ALVARENGA; WEBER; BOLSONI-SILVA, 2016), e muitos estudiosos do comportamento propõem que cada estilo parental resulta em níveis de desempenho e habilidades diferentes. Outros autores tem discutido a influência de diversas variáveis no comportamento adolescente que podem ser esclarecedoras e produzir encaminhamentos para intervenções promissoras (BANACO, 1995; BANDURA,1979; BARBOSA ROMERA LEME et al., 2016, CAMPOS; DEL PRETTE; DEL PRETTE, 2014; GOMIDE, 2001; SIDMAN; ANDERY; SÉRIO, 1995; SILVARES, 2001).

Apresenta-se a seguir uma breve discussão de algumas destas variáveis, a saber: Estilos Parentais, Educação ou Formação Sexual, Aquisição de Repertório Comportamental, Relações Funcionais Desadaptativas e Desenvolvimento de Autocontrole.

\subsection{ESTILOS PARENTAIS}

Os estilos parentais tem sido alvo de investigação na influência do desenvolvimento dos filhos (VALENTE, 2016). A revisão de literatura de Rios, 
Ferreira e Batista (2016) encontrou dez estudos realizados entre 2008 e 2014, no Brasil, que investigaram a influência do estilo parental no comportamento dos filhos no contexto escolar, em situações de diagnósticos e na prevenção e uso abusivo de drogas.

Denomina-se estilo parental "um conjunto de comportamentos e atitudes dos pais e todo o clima existente em uma relação pais-filhos, inclusive a expressão corporal, o tom de voz, o bom ou mau humor e as práticas parentais usadas mais frequentemente." (WEBER, 2005, p. 61)

Os estilos parentais podem ser nomeados de acordo com a forma que combinam dois fatores importantes da educação: responsividade (afeto) e exigência (regras/limites). (BAUMRIND, 1966/1971). Uma situação ótima para o desenvolvimento é aquela em que o nível de controle/poder gradualmente se altera em favor da criança, promovendo autonomia e na qual, as relações são mais positivas e calorosas. (CECCONELLO; ANTONI; KOLLER, 2003).

Cecconello, Antoni e Koller (2003) descreveram quatro estilos parentais formados a partir da combinação dos fatores exigência (comportamentos parentais relacionados à supervisão e disciplina/estabelecimento de limites) e responsividade (refere-se ao afeto, apoio e aquiescência). Os estilos propostos pelos autores são: Participativo, Autoritário, Permissivo e Negligente.

No estilo participativo ou autoritativo a exigência e a responsividade se equilibram, os filhos se sentem amados, valorizados, mas desenvolvem respeito mútuo e responsabilidade. "O desenvolvimento da autonomia é favorecido, pois os sentimentos e opiniões do filho são considerados, os pais dispõem de tempo para a família, e os melhores resultados são obtidos quanto à elevada autoestima, menor nível de estresse e de depressão, maior otimismo, habilidades sociais e percepção de auto eficácia” (BAUMRIND, 1966/1971, p. 69).

O desenvolvimento de boa autoestima, comunicação e habilidades sociais característico do estilo Participativo, além do equilíbrio entre limites e afeto, tornaria esta prática parental a mais adequada na prevenção da gravidez na adolescência, pois o adolescente estaria mais seguro para resistir a eventuais pressões e pronto a respeitar limites.

O Estilo Autoritário define as situações familiares nas quais há muito limite e pouco afeto. Há muita exigência e pouca responsividade e envolvimento. 
Apesar deste estilo promover desempenho escolar razoável e poucos problemas de comportamento, os filhos tendem a apresentar habilidades sociais pobres, baixa autoestima e alto índice de depressão e estresse. São mais submissos e creem que devem fazer tudo que for exigido para serem amados. Segundo Cecconello et al. (2003), o controle excessivo prejudica também o desenvolvimento da autonomia.

O estilo autoritário prejudica a comunicação com os pais e torna o ambiente familiar coercitivo, além de não favorecer o desenvolvimento da assertividade, sendo que este fatores são descritos por vários autores como relacionados à gravidez precoce (GUIMARÃES E WITTER, 2007; DIAS; GOMES, 2015; COSTA et al., 2014).

O estilo Permissivo é aquele em que há muito afeto e há pouco limite. Os pais permitem quase tudo ao filho, valorizam-no, oferecem bens materiais em excesso, consideram suas opiniões e necessidades, e não impõem sua autoridade como pais. O resultado geralmente é um desempenho fraco nos estudos e pode favorecer comportamentos antissociais.

Apesar dos filhos desenvolverem boas habilidades sociais e baixo índice de depressão, têm pouca tolerância à frustração, e dificuldade em seguir regras, o que seria importante no desenvolvimento do autocontrole. Também mostramse geralmente inseguros quanto à própria capacidade de realizar as coisas por si mesmos (WEBER, 2005).

A dificuldade de tolerar a frustação (não ter seu desejo imediato saciado) torna o estilo permissivo um fator de risco para a gravidez precoce, uma vez que a excitação sexual pode levar ao engajamento em sexo não planejado e não seguro. A dificuldade em seguir regras, também favorecida pelo estilo permissivo, é outro fator de risco para o comportamento sexual não seguro dos jovens, que podem ser indiferentes a orientações úteis e protetivas como adiar o início da vida sexual ou usar preservativos, por exemplo.

No estilo Negligente é apresentado pouco limite e também pouco afeto. São pais que permitem quase tudo e não tem interesse nem tempo para a educação e convivência com os filhos. Os pais que apresentam estilo negligente geralmente são confusos e não sabem como agir em relação ao filho, gerando inconsistência nas regras que tentam impor, não conseguindo fazer com que sejam cumpridas.

Este estilo apresenta os piores resultados com desempenho mais fraco em todas as áreas: tendência a comportamentos antissociais, fraco desempenho escolar, 
depressão, baixa autoestima, estresse, atraso no desenvolvimento e problemas comportamentais. Os filhos acreditam que não são e nem serão amados, e podem desenvolver alternativas antissociais para obterem a atenção (WEBER, 2005; VALENTE, 2016).

A baixa autoestima e comportamento antissocial promovidos pelo estilo negligente de educação tornam o adolescente especialmente vulnerável a buscar afeto e autoafirmação no sexo, além de não importar-se em transgredir regras, possivelmente para receber atenção dos pais, criando uma condição favorável ao comportamento sexual não seguro.

\subsection{EDUCAÇÃO SEXUAL}

A resposta sexual humana difere da resposta animal, pois esta última é padronizada, ou seja, a "variabilidade nas formas de reação sexual intra-espécie é mínima". (SILVARES, 2001, p. 78). Para os humanos, seu comportamento sexual depende em grande parte da aprendizagem anterior, e seu primeiro desempenho será deficiente, tendendo a melhorar com a prática e com orientações recebidas (SILVARES, 2001). Pode-se concluir daí a importância capital da formação recebida pelo ambiente social no desenvolvimento da sexualidade.

Segundo De Luca (1980) a família pode contribuir para o desencadear de uma gravidez precoce, comumente quando há falta de diálogo entre pais e filhos gerando atitudes ora autoritárias e coercitivas, ora permissivas e acomodadas. Gomide (2001), Gomide e Pinsky (2004) e Valente (2016) descrevem padrões de interação familiar que contribuem no desenvolvimento de comportamento antissocial que vão ao encontro do proposto por De Luca (1980) no que diz respeito ao desenvolvimento do comportamento desadaptado de colocar-se em risco de gravidez na adolescência ou uso de drogas, tais como: disciplina relaxada, punição inconsistente, falta de monitoria e negligência. Estes comportamentos parentais estão relacionados aos estilos autoritário e negligente.

Por outro lado, Silvares (2001) descreve padrões familiares que podem exercer papel importante na prevenção de problemas de saúde relativos ao sexo, a saber: "ambiente de integridade e respeito entre pais e filhos, especialmente 
nas relações interpessoais mais íntimas", e "informação na infância sobre os mais diferentes aspectos da sexualidade, assentada no entendimento de que a resposta sexual é natural e deve ter condições de expressividade espontânea” (p. 83).

A expressividade espontânea da sexualidade infantil não se refere a comportamentos inadequados socialmente, como a masturbação em público (que deve ser manejada com orientação e cuidado) ou eroticidade precoce da criança como algumas práticas culturais contemporâneas têm favorecido.

O estilo de vida urbano da sociedade contemporânea estabelece contingências que podem favorecer a incidência de problemas na adolescência, como uso de drogas, violência ou sexualidade precoce. A maturidade sexual se estabelece precocemente em virtude da intensa eroticidade do ambiente (programas de televisão, revistas, música, internet e outros), e maiores oportunidades e incentivo ao contato sexual casual (DE LUCA, 1980).

Não raro a apresentação da sexualidade na mídia se dá de forma violenta, desrespeitosa, irresponsável ou sexista. Segundo Silvares (2001) a TV poderia se constituir num meio auxiliar produtivo de educação sexual, mas ao invés disso tem produzido a erotização precoce das crianças, além de bombardeá-las com cenas de relações sexuais desrespeitosas. A dificuldade de monitoria eficiente sobre o conteúdo acessado na mídia e em especial na internet possibilita experiências de estimulação precoce e possivelmente traumática, além de favorecer a pedofilia e abuso sexual.

Dada a importância capital da influência ambiental e social no desenvolvimento da sexualidade, pode-se supor que medidas educativas que atuem na formação sexual da criança e adolescente, prevenção da erotização precoce e intervenções, visando enriquecer as relações familiares venham a contribuir para a prevenção da gravidez precoce.

\subsection{APRENDIZAGEM E DESENVOLVIMENTO DA PERSONALIDADE}

Com o advento da adolescência muitas transformações físicas favorecem o questionamento e mudança dos modelos e padrões infantis. O desenvolvimento do novo repertório comportamental propiciado pelo desenvolvimento biológico, 
recebe a influência do ambiente sociocultural por meio da aprendizagem, e esta última influência tem maior papel na determinação do seu desenvolvimento psicológico ou personalidade (BAUM, 2009).

Haydu (2003) aponta para o fato de que o desenvolvimento e adaptação do indivíduo ocorre exatamente pela ampliação de seu repertório comportamental, e através da formação deste repertório é que cada pessoa se individualiza, "deixa de ser um organismo moldado exclusivamente pelos determinantes genéticos, passando assim, a constituir-se como um indivíduo" (p. 112). Esta personalidade ou padrão comportamental poderá se desenvolver em várias direções dependendo da experiência individual, tais como: na direção do autocontrole, responsabilidade consciente e seguimento de regras sociais, ou em direção ao contra controle, impulsividade e irresponsabilidade.

Tanto a adolescência como a gravidez implicam em mudanças importantes e complexas, levando o indivíduo a aprender novas formas de responder ao ambiente (BANACO, 1995). E como a aprendizagem acontece?

Através do comportamento verbal as pessoas "podem aprender com o relato das experiências de outros (HAYDU, 2003, p. 125)", ou seja, sem experimentar as consequências de cada tentativa e erro ou acerto, por meio de regras ou instruções. Esta 'economia' de consequências possivelmente aversivas é fundamental para o objeto desta pesquisa, pois o ideal é que os jovens não precisem experienciar a gravidez para aprender a preveni-la no futuro. Esta forma de aprendizagem depende basicamente de reforçamento social.

O estilo participativo favorece a comunicação e troca de experiências, que poderia favorecer a aprendizagem por instruções. $\mathrm{O}$ estilo autoritário prevê muitas regras, mas a aprendizagem não será tão significativa se for acompanhada dos efeitos aversivos da punição ou monitoria excessiva, que promove contra controle. Adiante discutiremos como o controle social se torna conflituoso ou ambíguo no que se refere ao comportamento sexual adolescente.

Os indivíduos podem aprender também por modelagem (aperfeiçoando o comportamento de acordo com suas consequências), por modelação/aprendizagem vicariante (quando o indivíduo testemunha o comportamento de outro e suas consequências) e por imitação - que não implica necessariamente que o indivíduo 
tenha contato com as consequências do comportamento do outro. Assim, nem toda imitação produz consequências muito vantajosas, ou seja, a imitação reproduz fielmente o comportamento que o indivíduo observou, e não suas consequências. Inicialmente a imitação é reforçada pelos pais por ser importante na aprendizagem de ações como andar, alimentar-se e falar. Depois de instalado o repertório, as consequências produzidas pelo próprio comportamento será suficiente para mantê-lo. (HAYDU, 2003).

Skinner (1998) explica a participação do jovem no grupo analisando a imitação. "Em geral, comportar-se como os outros se comportam tem grande probabilidade de ser reforçado" (p. 341). De acordo com Bandura (1979), quando o comportamento de imitação é valorizado pelo grupo (é positivamente reforçado) e respostas diferentes não são recompensadas ou são até punidas (por estar destoando do grupo), a imitação do comportamento do outro será muito provável, ou seja, começa a se tornar "compulsória" ou automática. Comportar-se sexualmente mais por imitação do que pelas consequências negativas apontadas verbalmente, poderia favorecer o comportamento sexual de risco, que resulta na gravidez precoce.

Assim, o modelo fornecido pela mídia e pelo grupo de pares (comportar-se sexualmente de forma inadequada) e a instrução (contingência verbal que aponta para os perigos da gravidez e necessidade de comportamento sexual adequado) são conflitivas. Além disso, pelo fato de as consequências do comportamento sexual inadequado serem tardias (o diagnóstico e consequências da gravidez ocorre semanas ou meses depois do ato sexual, o comportamento é fortalecido e mantido pelas consequências prazerosas que são imediatas.

\subsection{CONTINGÊNCIAS DE REFORÇAMENTO NA GRAVIDEZ PRECOCE}

Segundo Banaco (1995), devido às transformações psicológicas, fisiológicas e sociais decorrentes da adolescência, é comum que os jovens exibam alguns comportamentos de risco, como usar drogas e fazer sexo sem qualquer método preventivo. Os comportamentos-problema, segundo ele, podem ser esquivas a estímulos aversivos do ambiente, ou seja, o jovem abusa de drogas e busca outros 
prazeres imediatos para fugir de ou evitar sentimentos provenientes de um ambiente ou situação aversiva.

Sidman; Andery e Sério (1995) argumentam que a gravidez e um casamento precoce podem representar uma fuga dos adolescentes da convivência em uma família que possui um ambiente coercitivo. O seguimento de um modelo fornecido pelos próprios pais que se afastam da família por alcoolismo, excesso de trabalho, excesso de televisão, e divórcio; também são possibilidades explicativas. Nesse caso a fuga e esquiva é dos pais, e o jovem aprende por imitação. As pesquisas apontam ainda para o grande número de adolescentes grávidas filhas de mães que também engravidaram na adolescência (AMORIM et al., 2009).

A influência exercida pelo grupo de pares pode ocorrer não apenas pelo reforçamento positivo (sensação de pertencimento, elogio, ascensão social no grupo) como também pela coerção, pois destoar do grupo ou contrariá-lo poderia produzir sanções e punições veladas ou manifestas. Assim, imitar o comportamento sexual de risco como promiscuidade e sexo não seguro, poderia constituir-se fuga e esquiva de punição (GOMES, 2016).

A influência do grupo de pares tem grande valor explicativo no uso de drogas ilegais por adolescentes (VALENTE, 2016; GOMES, 2016), mediante a necessidade de estar num grupo social que lhes assegure uma identidade. Segundo o autor do estudo, a presença de recursos suficientes para resistir às pressões do grupo (habilidades sociais como a assertividade, por exemplo) são imprescindíveis para a proteção ao comportamento desadaptado.

Fogaça (2015) relata uma experiência de Treinamento em Habilidades Sociais para prevenção de condutas antissociais em adolescentes, e prescreve seu uso para redução de comportamentos de risco em vários contextos, pois a comunicação assertiva e habilidades de recusar e convencer seriam relevantes no desenvolvimento de uma vida saudável e segura.

Campos, Del Prette e Del Prette (2014) investigaram a importância das habilidades sociais na prevenção à depressão em adolescentes e encontraram que déficits de habilidades sociais estão associados a indicadores de depressão na adolescência, enquanto as habilidades sociais podem auxiliar no enfrentamento de situações estressantes, o que seria útil para resistir às pressões do grupo. 
Além da possibilidade do sexo inseguro funcionar como comportamento de fuga/esquiva como descrito até aqui, todo comportamento sexual é naturalmente reforçado, tendo sido selecionado filogeneticamente, assim como outros comportamentos interessantes para a preservação da espécie (BAUM, 2009).

O comportamento amoroso e carinhoso, considerado reforçador positivo para a maioria das pessoas, geralmente também está relacionado com a intimidade do toque físico e sexual. Principalmente no caso de pessoas privadas de toque físico e carinho suficiente, a estimulação sexual precoce pode funcionar como estímulo discriminativo poderoso, apontando para a possibilidade de obter amor e atenção por meio do sexo. Neste aspecto, adolescentes cujos pais apresentam estilo negligente estariam particularmente vulneráveis a esta busca de afeto no sexo, já que acreditam que não são e nem serão amados incondicionalmente (GOMIDE, 2001).

O estilo parental permissivo também predisporia o adolescente ao sexo inseguro, não como busca de afeto principalmente, mas pela busca do prazer, já que este estilo favorece a impulsividade e prejudica o desenvolvimento da tolerância à frustração e aos limites (GOMIDE, 2001). Portanto, a forma como as contingências são dispostas em alguns ambientes parecem favorecer o comportamento sexual precoce e inadequado, por funcionar como fuga/esquiva de estimulação aversiva (comportamento reforçado negativamente) ou obtenção de prazer imediato mediante privação ou falta de limites (comportamento reforçado positivamente).

\subsection{AUTOCONTROLE E AGÊNCIAS DE CONTROLE}

Segundo Skinner (1953/1998) o autocontrole é possível apenas quando um comportamento produz consequências tanto aversivas quanto positivas, e é definido como uma parte do repertório comportamental de uma pessoa, exercendo controle sobre outra parte deste mesmo repertório. Frequentemente o comportamento que exige autocontrole se caracteriza por apresentar uma consequência imediata, que concorre com outra consequência adiada, ou atrasada.

Quando o comportamento produz uma consequência reforçadora imediata e outra aversiva a longo prazo, o autocontrole precisa ser exercido no sentido de enfraquecê-lo. Por outro lado, quando o comportamento em questão produz 
consequências aversivas imediatas e positivas a longo prazo, o autocontrole se dirige no sentido de emiti-lo e fortalecê-lo. (SKINNER, 1953/1998).

Apresentar comportamentos de autocontrole significa também uma aprendizagem de exposição e tolerância a sentimentos negativos (tristeza, raiva, frustração) e, possivelmente, escolha de cursos de ações menos danosos à saúde (CAMPOS; DEL PRETTE; DEL PRETTE, 2014).

Uma tentativa de solucionar o conflito provocado por consequências imediatas e atrasadas, que prejudiquem o indivíduo e, por consequência o grupo, se dá pela intervenção da comunidade através de agências de controle, ao apresentar consequências aversivas mais imediatas, com o objetivo de fortalecer comportamentos de interesse para o grupo e evitar o comportamento que produzirá consequências aversivas atrasadas, consideradas mais danosas. Outra intervenção das agências controladoras se dá pela modelagem do comportamento de seguir regras e de autocontrole (SKINNER, 1953/1998). O comportamento responsável é valorizado e recompensado.

Visto que o comportamento sexual inadequado envolve consequências positivas imediatas - geralmente a consequência imediata é mais eficaz para controlar o comportamento do que uma consequência atrasada - a probabilidade de ocorrência será grande a menos que ocorra a aprendizagem prévia de seguir regras e autocontrolar-se (abrir mão do prazer para evitar a consequência negativa a médio e longo prazo).

Skinner (1953/1998) aponta para o fato de que grande parte do autocontrole no ser humano é culturalmente determinado, em especial pelas agências éticas, religiosas e governamentais, que reforçam ou punem a conduta adequada ou inadequada:

O indivíduo 'amoral' que foge a essa influência mostra o efeito de pouco controle, enquanto o indivíduo completamente 'inibido' ou restringido se coloca no outro extremo... na medida em que seu comportamento ...foi reforçado ou punido como certo ou errado, legal ou ilegal, piedoso ou pecaminoso. (SKINNER, 1953/1998, p.460).

Skinner (1953/1998) afirma ainda que "o adolescente de hoje é afetado 
por técnicas conflitivas" de controle sexual. Segundo ele, o controle religioso e governamental seguem ainda o padrão mais antigo e severo, de remoção de todos os estímulos sexuais e punição a qualquer comportamento sexual, que gerava "efeitos neuróticos" nos indivíduos; entretanto grande parte das agências educacionais e familiares têm adotado um controle mais liberal, onde "reconhece-se que a ansiedade com respeito ao comportamento sexual é desnecessária [...] fornece-se um conhecimento da anatomia e função do sexo... e se evita a punição severa em favor da instrução sobre suas consequências"(p. 457-458).

Esta última técnica de controle mais liberal, segundo Skinner (1953/1998), pode não ser tão efetiva quanto as anteriores para controlar o comportamento sexual e produzir maior autocontrole numa situação de grande motivação (privação de afeto, sexual, de aprovação, etc). Ainda outras consequências podem concorrer com a esquiva da consequência liberada pela agência de controle, como quando há possibilidade de perda do parceiro ou quando o sexo funciona como esquiva de críticas.

Assim, para que uma pessoa tenha um comportamento sexual adequado é preciso que tenha aprendido anteriormente o comportamento de seguir regras e autocontrolar-se. Formiga (2016) estudou a importância do desenvolvimento de valores humanos sociais (religiosidade, tradição, coletividade) além de valores humanos pessoais (prazer e emoção), e observou que uma maior afiliação dos jovens aos pais (pai e/ou mãe) e professores, era preditor de menor conduta antissocial e delitiva. O autor afirma que este envolvimento dos jovens com autoridades que conseguem ser modelos das normas sociais vigentes e fazê-las cumprir por limites claros, torna-os mais habilitados para internalizar os valores ou padrões convencionais.

Uma dificuldade que se apresenta nesta aprendizagem se dá pelo conflito entre as duas técnicas de controle apontadas por Skinner (uma muito punitiva e outra muito liberal), quando exercidas sobre o mesmo sujeito a um só tempo, como acontece em nossos dias, dificultando ainda mais a formulação de regras adequadas e úteis que descrevam bem as contingências, e a aprendizagem de autocontrole consistente. 


\section{CONCLUSÕES}

O objetivo deste artigo foi discutir algumas variáveis psicossociais que atuam como fatores de risco ou proteção para a gravidez na adolescência, a saber: os estilos parentais de educação, a educação sexual e história de aprendizagem, o reforçamento positivo e negativo, presente na influência exercida pelo grupo de pares e a coexistência de técnicas conflitivas de controle sexual.

Conclui-se que devido ao fato do comportamento sexual ser fortalecido por consequências prazerosas imediatas e das consequências do comportamento sexual não seguro serem tardias (diagnóstico e consequências da gravidez), tornamse necessárias medidas educativas que atuem na formação sexual da criança e adolescente.

Algumas medidas poderiam se basear na prevenção da erotização precoce e em intervenções visando enriquecer as relações familiares, visto que a forma como as contingências são dispostas em alguns ambientes, tais como práticas parentais de negligência, permissividade ou autoritarismo parecem favorecer o comportamento sexual precoce e inadequado, por funcionar como fuga/esquiva de estimulação aversiva ou fonte de afeto e prazer.

Outra medida que parece ser fundamental é o ensino do comportamento de seguir regras e autocontrolar-se, como aquele que está presente em um estilo parental participativo, que apresenta limites mas por outro lado desenvolve autonomia e autoestima. A autonomia protege o adolescente da dependência excessiva do grupo, e a autoestima o protege da busca de afeto no sexo casual. $\mathrm{O}$ diálogo e abertura para o esclarecimento das regras evita a confusão das posturas ambivalentes ou conflituosas no desenvolvimento de critérios de controle, e a firmeza no estabelecimento de limites favorece o desenvolvimento do autocontrole, inclusive o autocontrole sexual.

Parece correto afirmar, ainda, que a instrumentalização do adolescente para reagir de forma assertiva diante de um grupo, pessoas, ou ambiente coercitivo representa um fator de proteção para o sexo inseguro. Isto pode ser realizado por meio do treinamento de habilidades sociais, individualmente ou em grupos psicoterapêuticos, mas antes disso, dentro dos lares, em famílias que promovam a expressão de opiniões e assertividade.

Apesar da criação, nas últimas décadas, de eficazes programas de 
intervenção para problemas comportamentais infantis, é urgente tornar acessível os conhecimentos e habilidades capazes de ajudar as famílias na tarefa de educar, visando a prevenção de problemas através da intervenção nas condições de risco.

\section{REFERÊNCIAS}

ALMEIDA, T. M.; ROCHA, L. S. Gravidez na Adolescência: Reconhecimento do Problema para Atuação do Enfermeiro na sua Prevenção. ANAIS SIMPAC, v. 7, n. 1, 2017.

ALVARENGA, P. A.; WEBER, L. N. D.; BOLSONI-SILVA, A. T. Cuidados parentais e desenvolvimento socioemocional na infância e na adolescência: uma perspectiva analítico-comportamental. Revista Brasileira de Terapia Comportamental e Cognitiva, v. 18, n. 1, 2016.

AMORIM, M. M. R. et al. Fatores de risco para a gravidez na adolescência em uma maternidade-escola da Paraíba: estudo caso-controle. Rev. Bras. Ginecol. Obstet., Rio de Janeiro, v. 31, n. 8, p. 404-410, ago. 2009.

BANACO, R. A. Adolescentes e Terapia comportamental. In: RONGÈ, B. (Org.). Psicoterapia comportamental e cognitiva. São Paulo: [s.n.], 1998. p. 143-8,

BANDURA, A. Modificação do comportamento: principles of behavior modification. Trad. Eva Nick e Luciana Peotta. Rio de Janeiro, 1979.

BARBOSA ROMERA LEME, V. et al. Habilidades sociais e o modelo bioecológico do desenvolvimento humano: análise e perspectivas. Psicologia \& Sociedade, v. 28, n. 1, 2016.

BAUM, W. M. Compreender o Behaviorismo. [s.l.]: Artmed, 2009.

BAUMRIND, D. Current patterns of parental authority. Developmental Psychology Monograph, v. 4, n. 1, Pt.2, 1971. 
CAMPOS, J. R.; DEL PRETTE, A.; PEREIRA DEL PRETTE, Z. A. Depressão na adolescência: habilidades sociais e variáveis sociodemográficas como fatores de risco/proteção. Estudos e Pesquisas em Psicologia, v. 14, n. 2, 2014.

CECCONEllo, A. M.; ANTONI, C. de; KOLLER, S. H. Práticas Educativas, Estilos Parentais e Abuso Físico no Contexto Familiar. Psicologia em Estudo, Maringá, v. 8, n. esp., p. 45-54, 2003.

COSTA, M. A. et al. Fatores que obstam na comunicação entre pais e filhos adolescentes sobre sexualidade. Revista de Enfermagem da UFSM, v. 4, n. 1, p. 123-132, 2014.

CRUZ, M. S. da; CARVALHO, F. J. V.; IRFFI, G. Perfil socioeconômico, demográfico, cultural, regional e comportamental da gravidez na adolescência no Brasil. RCIPEA, 2016.

DE AZEVEDO, W. F. et al. Complicações da gravidez na adolescência: revisão sistemática da literatura. Einstein, 2015.

DE LUCA, L. O Problema sexual da adolescente. São Paulo: Almed, 1980.

DIAS, A. C. G.; GOMES, W. B. Sexualidade e métodos contraceptivos: A importância da comunicação em família. VIDYA, v. 23, n. 40, p. 14, 2015.

FOGAÇA, F. F. S. et al. Avaliação de habilidades sociais de adolescentes em conflito com a lei em interações com familiares e amigos: uma análise de metacontingências. Tese (Doutorado em Psicologia) - Universidade Federal de São Carlos, 2015.

FORMIGA, N. S. Teste de um modelo causal entre valores humanos e condutas desviantes em jovens. Salud \& Sociedad, v. 2, n. 1, p. 80-88, 2016.

GOMES, S.P.M. A Influência dos pares no comportamento delinquente dos 
jovens: Dados do ISRD-3. Dissertação - Universidade do Minho, 2016.

GOMIDE, P. I. C. Efeitos das práticas educativas no desenvolvimento do comportamento anti-social. In: MARINHO, M. L.; CABALLO, V. E. (Org.). Psicologia Clínica e da Saúde. Londrina: Ed. UEL, 2001. p. 55-75.

GOMIDE, P. I. C.; PINSKY, I. A Influência da mídia e o uso das drogas na adolescência: adolescência e drogas. São Paulo: Contexto, 2004. p. 54-67.

GUIMARAES, E. A.; WITTER, G. P. Gravidez na adolescência: conhecimentos e prevenção entre jovens. Bol. - Acad. Paul. Psicol., São Paulo, v. 27, n. 2, p. 167-180, dez. 2007.

HAYDU, V. B. Aprendizagem: desenvolvimento e adaptação. In: ZAMBERLAN, M. A. T. (Org.). Psicologia e prevenção: modelos de intervenção na infância e adolescência. Londrina: Eduel. 2003. p.103-139.

RIOS, J. B. S.; FERREIRA, D. F.; BATISTA, E. C. Práticas Educativas e Estilos Parentais: uma Revisão Bibliográfica da Literatura Brasileira. Revista Uniabeu, v. 9, n. 21, p. 17-31, 2016.

SANTOS, N. O. et al. A Gravidez na adolescência na favela Sururu de Capote em Maceió, Alagoas. Psicol. Hosp. (São Paulo), v. 12, n. 2, p. 45-64, dez. 2014.

SIDMAN; ANDERY; SÉRIO, MURRAY; ANDERY, M. A.; SÉRIO, T. M. Coerção e suas Implicações. [s.l.]: Psy, 1995.

SILVA, A. A. A. et al. Fatores associados à recorrência da gravidez na adolescência em uma maternidade escola: estudo caso-controle. Cad. Saúde pública, v. 29, n. 3, p. 496-506, 2013.

SILVA, J. C. B. et al. Mortalidade Materna em Adolescentes no Estado de Santa 
Catarina, 1996 a 2013. Revista de Saúde Pública de Santa Catarina, v. 8, n. 3, p. 34-44, 2015.

SILVARES, E. F. M. Sexualidade na infância: quando e como intervir. In: MARINHO, M. L.; CABALlO, V. E. (Org.). Psicologia Clínica e da Saúde, Londrina: Ed. UEL, 2001. p. 55-75.

SKINNER, B. F. Ciência e Comportamento Humano. São Paulo: Martins Fontes, 1953/1998.

VALENTE, J. Y. Prevenção do uso de drogas na adolescência: intervindo nos estilos parentais. Dissertação (Mestrado) - Programa de Pós-Graduação em Ciências da Saúde, Fundação Universidade Federal de Ciências da Saúde de Porto Alegre, 2016.

WEBER, L. Eduque com carinho: equilíbrio entre amor e limites. Porto Alegre: Juruá, 2005.

Recebido em: 13 de agosto de 2017 Aceito em: 26 de outubro de 2017 